OPEN ACCESS

Edited by:

Bernhard Ertl,

Universität der Bundeswehr

München, Germany

Reviewed by:

Bettina Hannover,

Freie Universität Berlin, Germany

Jessica Lauren Degol,

Pennsylvania State University,

United States

*Correspondence:

Elena Makarova

elena.makarova@unibas.ch

Specialty section:

This article was submitted to

Educational Psychology,

a section of the journal

Frontiers in Education

Received: 28 December 2018

Accepted: 11 June 2019

Published: 10 July 2019

Citation:

Makarova E, Aeschlimann B and Herzog W (2019) The Gender Gap in STEM Fields: The Impact of the Gender Stereotype of Math and Science on Secondary Students Career Aspirations. Front. Educ. 4:60. doi: 10.3389/feduc.2019.00060

\section{The Gender Gap in STEM Fields: The Impact of the Gender Stereotype of Math and Science on Secondary Students' Career Aspirations}

\author{
Elena Makarova ${ }^{1 *}$, Belinda Aeschlimann ${ }^{2}$ and Walter Herzog ${ }^{3}$ \\ ${ }^{1}$ Institute for Educational Sciences, University of Basel, Basel, Switzerland, ${ }^{2}$ Swiss Federal Institute for Vocational Education \\ and Training SFIVET, Bern, Switzerland, ${ }^{3}$ Institute of Educational Science, University of Bern, Bern, Switzerland
}

Studies have repeatedly reported that math and science are perceived as male domains, and scientists as predominantly male. However, the impact of the gender image of school science subjects on young people's career choice has not yet been analyzed. This paper investigates the impact of the masculinity image of three school subjects-chemistry, mathematics, and physics - on secondary students' career aspirations in STEM fields. The data originated from a cross-sectional study among 1'364 Swiss secondary school students who were close to obtaining their matriculation diploma. By means of a standardized survey, data on students' perception of masculinity of science school subjects were collected using semantic differentials. The results indicate that for both sexes, math has the strongest masculinity attribution, followed by physics as second, and, finally, chemistry with the lowest masculinity attribution. With respect to gender differences, our findings have shown that among female students, the attribution of masculinity to the three school subjects does not differ significantly, meaning that female students rated all subjects similarly strongly as masculine. Within the group of male students however, the attribution of masculinity to math compared to chemistry and physics differs significantly, whereas the attribution of masculinity to chemistry and physics does not. Our findings also suggest that gender-science stereotypes of math and science can potentially influence young women's and men's aspirations to enroll in a STEM major at university by showing that a less pronounced masculine image of science has the potential to increase the likelihood of STEM career aspirations. Finally, the paper discusses ways of changing the image of math and science in the context of secondary education in order to overcome the disparities between females and males in STEM.

Keywords: gender, career aspirations, science, mathematics, secondary school students

\section{INTRODUCTION}

Gender segregation in the vocational orientation of adolescents has been well documented for decades in most OECD countries (OECD, 2006, 2012). The persistence of gendered paths in career choices has recently been reflected in the current Global Gender Gap Report of the World Economic Forum (WEF), which states that on average men are underrepresented in the fields of education, health and welfare whereas women are underrepresented in the STEM 
fields (WEF, 2017, p. 31). Moreover, on the basis of the occupational aspirations of 15-year-old adolescents, the prognosis for change in gender-based disparities in occupational and academic choices suggests that gender segregation in the education and labor market will remain persistent (OECD, 2017).

The persistence of horizontal gender segregation in educational and occupational fields contributes decisively to the spread of gender-stereotypic beliefs about a natural fit of women in careers in more expressive and human-centered fields and men in technical and math-intensive fields (Charles and Bradley, 2009). Gender stereotypes are part of a broader belief system that includes attitudes toward female and male family roles, female and male occupations, and gender-associated perceptions of the self. As bipolar constructs, gender stereotypes imply that what is masculine is not feminine and vice versa (Deaux and LaFrance, 1998; Worell, 2001; Renfrow and Howard, 2013). The social role theory (Eagly and Wood, 2012) suggests that gender roles and their occupants are highly visible in everyday contexts and that gender stereotypes emerge in response to the observation of women and men in different social roles and in role-linked activities related to occupational choices (Koenig and Eagly, 2014). This theoretical assumption was confirmed in a study by Miller et al. (2015), which analyzed how women's enrollment in science courses relates to the gender-science stereotype. Based on a survey of about 3,50,000 participants in 66 nations, this study concluded that explicit and implicit national gender-science stereotypes were weaker in countries with a higher female enrollment in tertiary science education. This study also demonstrated that stereotypes about science were strongly gendered, even in countries with high overall gender equity. In addition, a meta-analysis of two major international data sets- "Trends in International Mathematics and Science Study" (TIMMS) and the "Programme for International Student Assessment" (PISA)-has confirmed that gender equity in education is important not only for girls' math achievement but also for girls' self-confidence and valuing of mathematics (Else-Quest et al., 2010). Furthermore, a cross-national data analysis has indicated that gender differences in math are closely related to cultural variations in opportunity structures for girls and women, in particular to gender equity in school enrollment, women's share of research jobs, and women's parliamentary representation (ibid., p. 103). Accordingly, the low proportion of women in STEM leads to the spread of a gender stereotypical image of math and science as a male domain and beliefs about male supremacy in technical and math-intensive fields. In turn, such beliefs affect young people's career choices, leading to a mutual reinforcement of gender stereotypes, and gender gaps in career related interests and choices (Nosek et al., 2009, p. 10,596).

In Switzerland gender segregation is also persistent and is especially noticeable in the STEM field (FSO, 2013). In educational tracks at the universities of applied science, with only $21.3 \%$ of women enrolled in STEM courses in academic year 2017-2018. However, some STEM fields are more strongly gender segregated than others. The lowest proportion of women is in the fields of informatics (10.4\%) and technology (8.5\%), whereas in the fields of chemistry and life-sciences the proportion of women is considerably higher (43.7\%) (FSO, 2019a). In secondary education, gender is almost balanced in chemistry and biology (girls $18.4 \%$ and boys $20.5 \%$ ) as a subject of specialization, whereas considerably more boys (18.4\%) than girls $(4.4 \%)$ decided to specialize in the subjects math and physics (FSO, $2019 b)$. It is, thus, important to distinguish between different STEM disciplines and subjects when addressing the gender gap in the STEM field (Rosser, 2012; Ertl et al., 2017).

Following this notion, our study aimed to analyze the gender stereotype of school science subjects among female and male students and the impact of gender-science stereotypes on the career aspirations of young people. The ultimate goal of our study is to provide a more comprehensive understanding of gender equity in STEM.

\section{THE GENDER STEREOTYPE OF MATH AND SCIENCE}

The gender stereotype of math and science has been analyzed via a variety of quantitative and qualitative methods (review in Makarova and Herzog, 2015). Among those are the DrawA-Scientist Test (DAST) (e.g., Chambers, 1983; Finson, 2002; Scherz and Oren, 2006), the Implicit Association Test (IAT) (e.g., Greenwald et al., 1998; Nosek et al., 2002, 2009), explicit stereotype assessments using attitude questionnaires (e.g., Kessels, 2005), semantic differential assessments (e.g., Herzog et al., 1998; Makarova and Herzog, 2015), and individual or group interviews (e.g., Archer et al., 2010).

Studies that applied the DAST method reported that students from kindergarten to high school perceive a scientist as a male person. The children's drawings contained very few portrayals of female scientists and these few drawings were mostly drawn by female students. For example, in a study among students from kindergarten through fifth grade there were only 28 pictures of a female scientist out of 4,807 , and all of these 28 drawings were drawn by girls (Chambers, 1983); in a study surveying students in grades $2-12$ only 135 pictures out of 1,600 displayed female scientists and only six out of 135 pictures of a female scientist were drawn by male students (Fort and Varney, 1989); in a study among students of 9-12 years of age, there were only 72 pictures of a female scientist out of 223 , and of those 72 , only 13 pictures were drawn by male students (Huber and Burton, 1995). The precise way in which a scientist was pictured by middle school students was reported in a study by Scherz and Oren (2006, p. 977): "The common image was that of a scientist as a bespectacled male with unkempt hair in a white lab-coat." Moreover, the following quote from a study by Mead and Metraux (1957) on high-school students' image of a scientist highlights how persistent the scientist-stereotype remains over decades. The image of a scientist is depicted in students' essays as "a man who wears a white coat and works in a laboratory. $\mathrm{He}$ is elderly or middle aged and wears glasses ... He may wear a beard, may be unshaven and unkempt" (Mead and Metraux, 1957, p. 386). Finally, the most recent meta-analysis of five decades of U.S. DAST studies based on 78 studies $(N=$ 20,860 ) among children grades K-12, shows a growth in children's depictions of female scientists in later decades. However, the more female scientist appeared only in drawings by young 
children, but science was still associated with men among older children (Miller et al., 2018). The authors conclude that despite the increase of women's representation in science over the last decades, children still observe more male than female scientists in their social environments (Miller et al., 2018, p. 1,943).

Furthermore, research on gender stereotypes has revealed that science is not only associated with a male person, but that masculine traits are also attributed to it. A study by Archer et al. (2010) suggested that although young children do not have profound knowledge about science subjects, they attribute masculine traits to science at an early age. In the same vein, a study by Cvencek et al. (2011) reported that as early as second grade children perceive that math is a male domain, demonstrating the American cultural stereotype. In addition, a study among high school students reported that better performance in STEM subjects was attributed to boys, and masculine traits to a person who works as a scientist (Hand et al., 2017). Another study among school children and university students by Weinreich-Haste (1981) assessed the gender image of different academic subjects using ratings on a six-point masculine-feminine scale. The study reported that math, physics and chemistry had the strongest connotation as masculine academic subjects. Moreover, it showed that science subjects were not only rated as masculine but also associated with a set of attributes commonly associated with masculinity such as being hard, complex, based on thinking rather than on feelings (Weinreich-Haste, 1981, p. 220f.). In contrast, a study on gender perception of school subjects among students aged 11-12 years, which applied a seven-point masculine-feminine scale, reported that while physics was rated as significantly more masculine, chemistry and mathematics were rated as neither masculine nor feminine (Archer and MacRae, 1991).

To summarize, we can state that the male stereotype of science and of a scientist is persistent and appears as early as in kindergarten age, while the association of science with men is especially persistent among older children. Research has also shown that students predominantly perceive science subjects (math, physics, and chemistry) as a male domain, although findings do not provide a clear picture as to which of these subjects is more strongly associated with male gender. The reason is the very broad age-range of students $(\mathrm{K}-12)$ across reported studies, lack of comparison of gender stereotypes of different school subjects within one study, different methodology (explicit and implicit assessment) used to assess gender stereotypes of science, as well as the time span between findings of different studies. Thus, further research on the perception of masculinity of chemistry, math, and physics among school students is needed to gain deeper insight into the impact of the gender stereotypes of science subjects on STEM-career aspirations.

\section{GENDER DIFFERENCES IN THE PERCEPTION OF GENDER-SCIENCE STEREOTYPES}

Research on gender-science stereotypes has illustrated differences between female and male youth with respect to the endorsement of stereotypic beliefs about STEM. A study among primary school students illustrated that stereotypical beliefs that STEM school subjects are more suitable for boys than for girls were more strongly endorsed by boys than by girls. Moreover, this study has shown that students with stereotype-consistent interest in STEM-related school subjects were particularly likely to endorse gender-science stereotypes. Consequently, especially boys who were highly interested and girls who were relatively uninterested in STEM-related school subjects were more likely to believe that STEM school subjects constitute a male domain (BlaŽev et al., 2017). In line with this, a study among high school students has shown that girls reported lower self-efficacy in math and science compared to boys (Hand et al., 2017). Finally, a study among first-year university students indicated that negative stereotypes of women's engineering and mathematical ability were more strongly endorsed among male students, whereas female students were more likely to report higher perceptions of their engineering abilities (Jones et al., 2013).

With respect to the perception of different STEM disciplines, studies among adolescent youth have shown that female students show a more pronounced gender stereotype for math compared to male students, who are less likely to exhibit implicit genderstereotypic associations (Steffens et al., 2010). In line with these findings, a study by Nosek et al. (2002, p. 44) reported that even women who had selected math-intensive majors had difficulties in associating math with themselves because they associated math with the male gender. Also, studies that analyzed the gender stereotype of physics found that, among high school students, being interested in physics was associated with the male gender (Kessels, 2005; Kessels et al., 2006) and that, among girls, being interested in physics endangered their selfidentification with the female gender (Kessels et al., 2006). Furthermore, a typical teacher of mathematics and physics was imagined to be a man (Kessels and Taconis, 2012). Finally, a study among secondary school students in Switzerland showed that, among female students, the semantic profile of math and physics correlated negatively with the semantic profile of the female gender, whereas the semantic attributes of chemistry were significantly related neither to the male nor to the female gender. From the male students' point of view the semantic profile of math correlated negatively with the semantic profile of the female gender, whereas the semantic attributes of chemistry and physics were positively related to the semantic profile of the male gender. Whereas, the female gender was strongly associated with traits such as soft, playful, soulful, dreamy, lenient, frail, and flexible, among the semantic traits associated with math and physics were attributes such as hard, serious, distant, sober, strict, robust, and rigid. Overall, this study has shown that among the three school subjects analyzed in the study, math and physics were either negatively associated with female or positively associated with male gender. In contrast, chemistry was the least gender stereotyped because among female students there were no significant associations of the term chemistry with either gender term and among male students no negative association with the term woman (Makarova and Herzog, 2015). These findings are interesting in light of students' preference for their subject of specialization in secondary schools in Switzerland (FSO, 2019b) 
showing that chemistry is chosen almost equally often by boys and girls, whereas math and physics are largely avoided by girls as subjects of specialization. Accordingly, students' gender-related perception of different science subjects may differently impact their preferences of STEM subjects at school and vice versa.

To summarize, we can state that female and male students indicate different patterns of gender-science stereotype. It seems that male participants show more endorsement of the genderscience stereotype by regarding STEM subjects as more suitable for boys and attributing less abilities in the STEM disciplines to the female gender compared to the male gender. At the same time, female participants are more likely to associate math and science more strongly with the male gender and masculine traits than with the female gender and feminine traits. Finally, previous research has shown that school science subjects differ with respect to their gender-related connotation, and indicating that chemistry has the least pronounced masculine image among secondary school students.

\section{GENDER-SCIENCE STEREOTYPE AND CAREER ASPIRATIONS IN STEM}

The impact of the gender-science stereotype on students' interest in STEM subjects and their aspirations to pursue a career in STEM fields has been addressed from different perspectives.

Based on Eccles' expectancy-value model, which highlights the impact of culturally based stereotypes and identity-related constructs on educational and occupational choices (Eccles, 1994; Eccles and Wigfield, 2002), a number of studies have shown that academic self-concept and subject interests are among the most relevant determinants in students' selection of secondary school majors (Nagy et al., 2008). Similar mechanisms seem to be crucial for career choice or choice of a major in higher education (Nagy et al., 2006). A recent study among female students in STEM subjects with a low proportion of females revealed that gender stereotypes have a negative impact on students' STEM-specific self-concept even among students with good grades in STEM (Ertl et al., 2017).

According to the theoretical framework of Gottfredson (2002, 2005), occupational aspirations are incorporated in the individual self-image developed during socialization from early childhood through adolescence. The process of developing occupational aspirations is embedded in the comparison of one's self-image with the image of an occupation and one's judgment about the match between the two. In this process, the gender image of an occupation is especially crucial for career choice, because the "wrong" sex type of an occupation is more fundamental to self-concept than the prestige of an occupation or individual interests. Applying Gottfredson's theory, the significant impact of the gender image of an occupation on the process of career choice was confirmed in a number of studies (Ratschinski, 2009; Bubany and Hansen, 2011). Moreover, research suggests that girls are more likely to narrow their occupational choices because they perceive particular occupations as inappropriate for their gender. Accordingly, girls tend to shift their occupational aspirations to gender-typical occupational expectations more strongly than do boys. At the same time, boys' perceptions of occupations appear to be more gender-stereotypical (Hartung et al., 2005).

Research focusing on self-to-prototype similarity suggests that the lack of similarity between the self and an academic subject is linked to a lower probability of liking this subject or choosing this academic subject as a major (Kessels, 2005; Kessels et al., 2006; Taconis and Kessels, 2009). Moreover, the perceived closeness between the self and a school subject was predictive for youths' career choice intentions (Hannover and Kessels, 2004; Kessels et al., 2006). In the same vein, a study among ninth and tenthgrade students by Neuhaus and Borowski (2018) investigated whether the greater self-to-prototype similarity impacts students' interest in coding courses. This study revealed that, under the condition that course descriptions were related to communal goals, girls showed greater interest in learning to code compare to the agentic-goal condition of the course description (Neuhaus and Borowski, 2018, p. 233).

Likewise, a study among students and faculty reported that agentic traits are more strongly associated with success in science than communal traits, discouraging women from pursuing a science career (Ramsey, 2017). Another study among first-year undergraduate students illustrated that implicit stereotypes of science completely accounted for a gap in male and female students' interests to pursue science. Especially the academic aspirations of women who strongly identified as female were affected by the gender stereotypic image of science (Lane et al., 2012). In line with this, a study among first-year women engineering students reported that engineering identification was a significant predictor of persistence in engineering, and that this relationship was stronger for women than men (Jones et al., 2013). Finally, a study among undergraduate science majors demonstrated that a stronger gender-science stereotype has a diminishing effect on identification with science and science career aspirations among women, whereas, among men, a stronger gender-science stereotype boosts their identification with science and their career aspirations in science fields (Cundiff et al., 2013).

To summarize, we can state that gender-science stereotyping has been shown to hinder the self-identification of young women with STEM academic subjects and fields and also to negatively affect their self-concept and their subject interests. These, in turn, hinder female students from opting for a science major and pursuing a career in science. For male students, gender-science stereotyping seems to have the opposite effect and, thus, boosts their career aspirations in STEM.

\section{FOCUS OF THE STUDY}

Given that previous research has often focused on genderscience stereotypes of science in general or on stereotypical beliefs about single STEM disciplines, our study contributes to previous research by simultaneously analyzing the gender stereotype of different school science subjects-chemistry, math, and physics-among female and male students. These three science subjects were chosen because females are strongly underrepresented in math and physics within the educational 
sector and career fields, whereas chemistry has a more balanced gender ratio. This allows us to investigate the impact of genderscience stereotypes of different science subjects on students' aspirations to study STEM. In view of the theoretical and empirical framework of the study, we define the gender stereotype of three school subjects as the extent of association of each school subject with masculine traits (see section Measurements; masculinity index).

In terms of hypotheses, we firstly expected differences with respect to the degree of masculinity which students attribute to chemistry, math, and physics. We hypothesized that chemistry would be ascribed the lowest degree of masculinity compared to math and physics.

Secondly, we expected gender differences among secondary school students in the association of chemistry, math, and physics with male gender. We hypothesized that this association of the three science subjects with masculine traits would be stronger among female students.

Thirdly, we expected that the gender stereotype of math and science would affect female and male secondary school students' aspirations to enroll in a STEM major at university. We hypothesized that to the extent students conceive of STEMschool subjects as masculine they would be less inclined to aspire to enroll in a STEM major at university. We further hypothesized that stereotyping science subjects as masculine would have a greater negative impact on the STEM aspirations of female than male students.

\section{METHODS}

\section{Participants}

The study presented was part of the research project Gender atypical career choices of young women, a project embedded in the Swiss National Science Foundation's Research Program on "Gender Equality" (NRP 60). The study is based on quantitative data which originated from a standardized survey of 1,364 students in Swiss-German-speaking secondary schools. The study was carried out following the ethical principles and codes of the Faculty of Humanities at the University of Bern, which are based on international ethics codes (e.g., of the American Sociological Association and of the American Psychological Association). Accordingly, approval by an ethics authority was not required. Students were informed about the research project and participated in the survey voluntarily. Participants? Informed consent was implied through survey completion; therefore, they were not required to provide written consent to participate. Written parental consent was not necessary either, because all students had reached legal adulthood and could decide for themselves. After the survey all data were anonymized.

The surveyed students were close to obtaining their matriculation diploma (i.e., school leaving certificate), which in Switzerland permits entry into tertiary education. The participants were on average 19 years old $(S D=1.0)$. With regard to sex, the percentage of female students $(54.1 \%)$ was somewhat higher than that of male students (45.9\%).

\section{Measurements Masculinity Index}

Data on students' perception of the gender image of the school subjects chemistry, math, and physics were collected using semantic differentials (Makarova and Herzog, 2015). The semantic differential is one of the most popular techniques of explicit attitude assessment (Millon et al., 2003). An explicit measurement of the gender stereotype of science subjects was chosen over an implicit stereotype test, because the study focuses on the salient gender stereotypes of those subjects (Millon et al., 2003, p. 356). The semantic differential uses bipolar scales with contrasting adjectives at each end to measure people's reactions to stimulus words and concepts (Heise, 1970, p. 235). The methodological advantage of the semantic differential scale is that it highly adaptable in assessing respondents' connotative association with any concept (Osgood et al., 1957; Heise, 1970). The basic assumption of the semantic differential is that attitudes toward two associated concepts tend to converge and toward two dissociated (contrasted) constructs tend to diverge (Heise, 1970, p. 249). In our study attitudes toward gender and science were measured using semantic differentials consisting of 25 pairs of adjectives with semantically opposite meanings (e.g., hard-soft, strong-weak, robust-frail) to assess the connotations of the four terms man, chemistry, math, and physics on a seven-point scale $(1=$ greatly, $2=$ fairly, $3=$ somewhat, $4=$ neither, $5=$ somewhat, 6 = fairly, $7=$ greatly). This instrument is based on the original scale (Osgood et al., 1957) which was initially adapted to the German language by Hofstätter (1973) and then validated in Switzerland in two studies on the gender stereotype of school subjects (Herzog et al., 1998; Makarova and Herzog, 2015).

The student sample was divided into groups, with each group completing the semantic differential for one subject term and for the man term: chemistry and man $(n=406)$, math and $\operatorname{man}(n=512)$ and physics and man $(n=446)$. In order to avoid response bias, the semantic differential of the subject was introduced at the beginning of the questionnaire and the semantic differential of the term man at the end of the questionnaire. On the basis of these data we calculated a masculinity index by subtracting the 25 items of the man profile from the corresponding items of each subject profile and summing them up to a sum score for each student. At the end of this procedure one value for each student was calculated. For easier interpretation, this value was reversed; a negative value was transformed into a positive value and a positive value into a negative value. Accordingly, the masculinity index expresses the differentiation between high masculinity (low discrepancy between the profiles man and subject; $\max .=+6$ ) and low masculinity (high discrepancy between the profiles man and subject; $\min .=-6$ ). For example, a score of 5 on the masculinity index, indicates that the semantic profile of the respective subject (chemistry, math, or physics) and the semantic profile of the term man are very similar, meaning that the discrepancy between the two semantic profiles is low. Figure 1 illustrates our calculation. Moreover, the masculinity index is approximately normally distributed (Kurtosis $=2.09, S E=0.13$; Skewness $=0.47, S D=$ 0.07) (George and Mallery, 2016). 

$-2.40$
$+4.28$

high discrepancy

between the profiles

subject and man

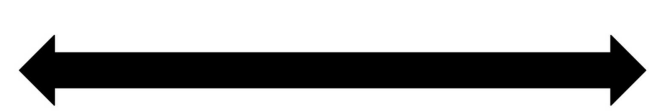

low discrepancy

between the profiles

subject and man

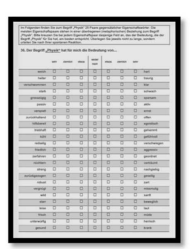

$\mathrm{M}=.20$

$\mathrm{SD}=.66$

$\mathrm{N}=1364$

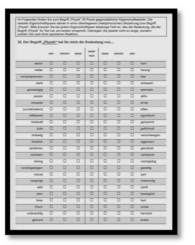

LOW MASCULINITY

\section{HIGH MASCULINITY}

FIGURE 1 | Masculinity index of chemistry, math, and physics.

\section{STEM Field Study Choice}

To assess the field of study choice, the secondary school students were asked about their subject preference for study at a university or at a university of applied sciences after the successful completion of secondary school. The answers were coded by the gender-type of the field of study, based on the gender distribution of master's degrees obtained at Swiss universities in the year 2010 (FSO, 2012). A field of study was labeled as female-atypical (male-typical) when the proportion of women who received a master's degree in that field was below 30 per cent. In our sample, Mathematics, Statistics, IT, the Natural Sciences and Engineering fall into this category. Since all listed fields of study can be assigned to the STEM area, the category is henceforth labeled STEM study choice. All other fields of study were assigned to the category "non-STEM study choice." The multivariate analyses were conducted with the dichotomous variable STEM field study choice (STEM field study choice = category 1 ; non-STEM study choice $=$ reference category 0 ).

\section{RESULTS}

\section{Attribution of Masculinity to Chemistry, Math, and Physics Among Secondary School Students}

The attribution of masculinity to the three science subjects among female and male students was subjected to a two-way ANOVA (school subject and students' sex). The overall model yielded an $F$ ratio of $F_{(5,1,355)}=15.83, p \leq 0.001$. With respect to the degree of masculinity attributed to the three science subjects, our analysis of variance indicated significant differences $F_{(2,1,355)}=10.76, p \leq 0.001$. Post-hoc comparisons (Bonferroni) has shown that the attribution of masculinity differs significantly between math and chemistry $(p \leq 0.001)$ and between math and physics $(p \leq 0.05)$. There were no significant differences in the attribution of masculinity to chemistry and physics. The
TABLE 1 | Descriptive statistics.

\begin{tabular}{llll}
\hline & All & Female & Male \\
\hline Masculinity of & $n=406$ & $n=240$ & $n=166$ \\
chemistry (min: -2.4, & $M=0.13$ & $M=0.27$ & $M=-0.09$ \\
max: 4.28) & $S D=0.71$ & $S D=0.66$ & $S D=0.72$ \\
Masculinity of math & $n=512$ & $n=242$ & $n=267$ \\
(min: -1.76, max: 2.36$)$ & $M=0.29$ & $M=0.38$ & $M=0.20$ \\
& $S D=0.64$ & $S D=0.62$ & $S D=0.64$ \\
Masculinity of physics & $n=446$ & $n=257$ & $n=189$ \\
(min: - 2.08, max: 3.08$)$ & $M=0.18$ & $M=0.31$ & $M=0.01$ \\
& $S D=0.63$ & $S D=0.66$ & $S D=0.55$ \\
\hline
\end{tabular}

$M=$ mean, $S D=$ standard deviation.

mean values indicated that math has the strongest attribution of masculinity, followed by physics as second, and finally chemistry with the lowest attribution of masculinity (see Table 1). With regard to the sex differences in the attribution of masculinity, our analysis of variance yielded significant differences between female and male students $F_{(1,1,355)}=63.20, p \leq 0.001$. The ascription of masculinity to the three science subjects turned out to be stronger among female than among male students (see Table 1).

The interaction effect between two factors school subject and students' sex was non-significant $F_{(2,1,355)}=2.34, p=$ $n s$. Nevertheless, to explore the interaction term in more detail we analyzed the attribution of masculinity to the three science subjects within the group of female and that of male students. For this purpose, the confidence intervals for the three science subjects were calculated. Within the group of female students, the attribution of masculinity to the three school subjects does not differ significantly, meaning that female students rated all subjects similarly as strongly masculine [95\% CIs: chemistry $[0.19,0.36]$, math $[0.30,0.46]$, and physics $[0.23,0.39]]$. Within the group of male students, however, the attribution of masculinity to math and chemistry [95\% CIs [0.12, 0.27], [-0.20, $0.02]]$ as well as to math and physics [[0.12, 0.27], [-0.07, 0.09]] 
TABLE 2 | Study choice.

\begin{tabular}{lllll}
\hline & All & Female & Male & $\begin{array}{l}\text { Interaction } \\
\text { of gender } \times \\
\text { study choice }\end{array}$ \\
\hline Study choice & $N=1,618$ & $n=873$ & $n=742$ & $x^{2}=58.26^{\star \star \star}$ \\
STEM choice & $16.6 \%$ & $10.1 \%$ & $24.3 \%$ & \\
NON-STEM choice & $83.4 \%$ & $89.9 \%$ & $75.7 \%$ & \\
\hline
\end{tabular}

The interaction of gender $\times$ study choice is significant at the ${ }^{* \star *} p \leq 0.001$ level, $x^{2}=$ $x^{2}$-value (chi-square-test).

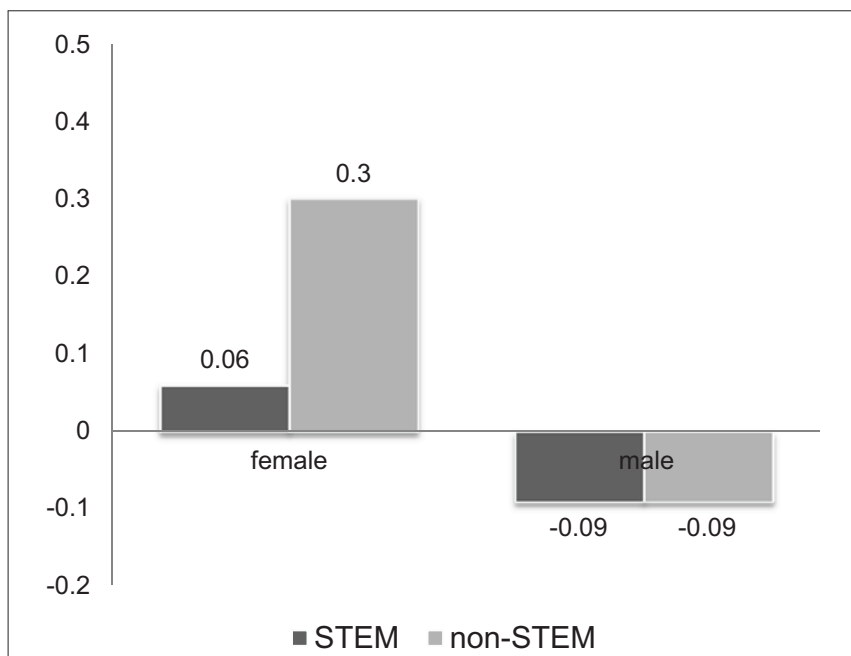

FIGURE 2 | Masculinity index of chemistry and career aspirations.

differs significantly, whereas the attribution of masculinity to chemistry and physics does not $[[-0.20,0.02],[-0.07,0.09]]$.

\section{Gender Stereotype of Chemistry, Math and Physics and Students' Study Aspirations}

First, we analyzed career aspirations among the secondary school students by carrying out $x^{2}$-test (chi-square test) for the binomial dependent variable STEM study choice (see Table 2). Overall, one sixth of all students aspired to having a STEM major (16.6\%). However, aspirations to study STEM subjects were not equally distributed between men and women. While among men every fourth student $(24.3 \%)$ planned to study STEM, among women only every tenth student (10.1\%) was interested in STEM studies.

Second, we analyzed the attribution of masculinity to school subjects (chemistry, physics, and math) among secondary school students who had chosen a STEM compared to those students who had chosen a non-STEM major (Figures 2-4).

Our analysis reveals the following findings for each subject:

- Chemistry (Figure 2): With respect to career aspirations of young women, our results show that female students who opt for a non-STEM study major connotated chemistry significantly strongly as masculine compared to young women with a STEM career choice $(p \leq 0.01)$. Among young men there were no significant differences in the attribution
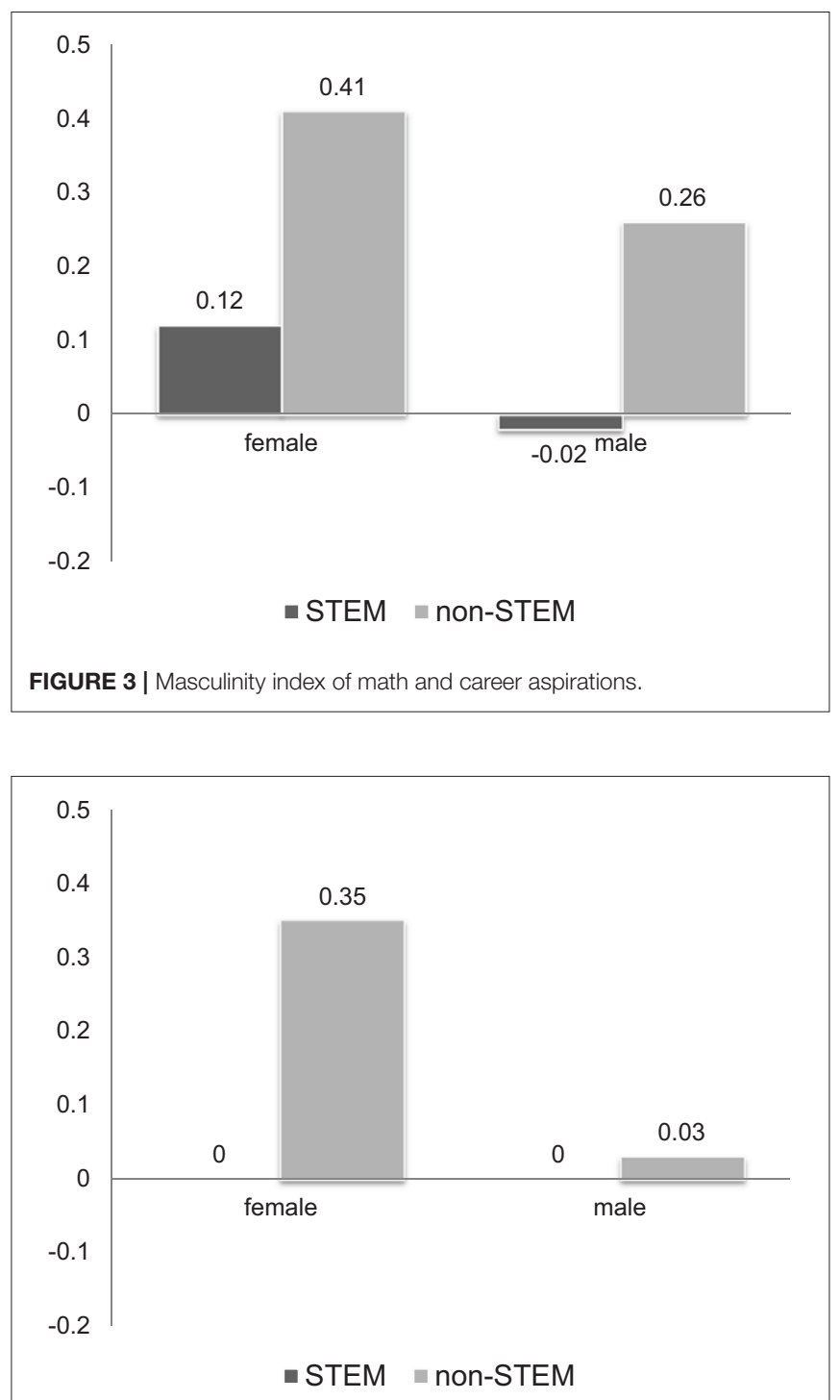

FIGURE 4 | Masculinity index of physics and career aspirations.

of masculinity to the subject chemistry between students who had chosen STEM and those who had chosen another study field.

- Math (Figure 3): Our results show that among female and male students who had potentially chosen a non-STEM major, the attribution of masculinity to math was significantly higher compared to youth with a STEM career choice (female: $p \leq$ 0.05; male: $p \leq 0.001$ ).

- Physics (Figure 4): Considering female students who had potentially chosen a non-STEM study major, physics was significantly more highly stereotyped as a masculine subject compared to young women with a STEM career choice $(p \leq 0.001)$. Among young men there were no significant differences in the attribution of masculinity to the subject physics between male students who had chosen STEM and those who had chosen another study field. 
To sum up, young women who aspire to study a STEM major stereotype the three subjects as less strongly masculine compared to young women who aspire to study non-STEM subjects. Among young men, only math was rated as highly masculine among those students who had chosen a non-STEM study program. Thus, for young women as well as for young men with a non-STEM career choice, math has a highly masculine image. What is interesting is that even young women who opt for a STEM field rate the subjects-except physics—as masculine, though only slightly.

Finally, Generalized Linear Models (GzLM) were estimated (McCullagh and Nelder, 1989) to shed light on the impact of the gender image of math and science on the likelihood that female and male students aspire for a STEM field of study. The procedure modeled the choice of a STEM study major as the response category, with all other study fields as the reference category (non-STEM). We aggregated the masculinity index for math and the two science subjects for the model of female students, because separate models showed nearly the same effect for each individual subject, and therefore we could increase the power of the model in terms of cases. The model for male students included only the masculinity index of math as a predictor, since there was no significant effect for science subjects between young men who had chosen STEM and non-STEM ones (see also Figures 2, 4). We report the $\operatorname{Exp}(\beta)$, which indicates the likelihood of an occurrence of the tested effect. If the value is below 1, the likelihood decreases; if it is above 1 , the likelihood increases.

Table 3 shows the first model estimated for female students [Likelihood Ratio $x_{(1,739)}^{2}=17.09, p \leq 0.001$, Pearson-ChiSquare $60.95(88,739)=0.69]$. The findings reveal that a strong masculine image of math and science decreases the likelihood of young women choosing a $\operatorname{STEM}$ study $(\operatorname{Exp}(\beta)=0.44 ; p \leq$ $0.001)$. In other words, if young women do not perceive math and science as predominantly masculine, they opt significantly more often for studying a STEM major.

The second model was estimated for male students [Likelihood Ratio $x_{(1,267)}^{2}=9.22, p \leq 0.01$, Pearson-ChiSquare $73.90(66,267)=1.12]$. The results show that the masculinity of math is also a predictor of young men's career aspirations. The higher the masculinity image, the lower the likelihood of a STEM study choice $(\operatorname{Exp}(\beta)=0.48 ; p \leq 0.01)$.

To conclude, both models show that the image of chemistry, math and physics has an impact on students' career intentions. If the image of the three subjects has strong masculine connotations, career choice is unlikely to be within the STEM field.

\section{DISCUSSION}

This study contributes to the line of research on the gender stereotype of science by analyzing the gender-related image of three school subjects. It provides, moreover, more refined knowledge on the impact of gender stereotypical perception of
TABLE 3 | Impact of the masculine image of math and science on secondary students' career aspirations.

\begin{tabular}{|c|c|c|c|c|}
\hline Parameter & $\beta$ & SE & $\begin{array}{l}\text { Wald-Chi- } \\
\text { Square }\end{array}$ & $\operatorname{Exp}(\beta)$ \\
\hline \multicolumn{5}{|c|}{ Math and science model for female students } \\
\hline (Intercept) & $-1.98^{\star \star \star}$ & 0.12 & 253.81 & 0.14 \\
\hline $\begin{array}{l}\text { Masculinity of math and } \\
\text { science }\end{array}$ & $-0.82^{\star \star \star}$ & 0.17 & 24.30 & 0.44 \\
\hline (Scale) & $1^{\mathrm{a}}$ & & & \\
\hline \multicolumn{5}{|c|}{ Math model for male students } \\
\hline (Intercept) & $-1.17^{\star \star \star}$ & 0.15 & 59.88 & 0.31 \\
\hline Masculinity of math & $-0.73^{\star \star}$ & -0.23 & 9.91 & 0.48 \\
\hline (Scale) & $1^{\mathrm{a}}$ & & & \\
\hline
\end{tabular}

Generalized Linear Model (binomial/logit). Dependent variable: STEM career (response) vs. Non-STEM Career (reference); ${ }^{a}$ Fixed at the displayed value; $\beta=$ regression coefficient; $S E=$ standard error; ${ }^{* * *} p \leq 0.001,{ }^{* *} p \leq 0.01$.

math and science on female and male secondary school students' choice to enroll in a STEM university degree program.

In line with the findings of a study by Weinreich-Haste (1981), our results reveal that students not only perceive chemistry, math and physics as masculine, but also that there is a considerable difference in the strength of the association of each subject with the male gender. According to our findings, math is most strongly perceived as a masculine subject among female and male secondary school students, followed by physics and then chemistry, which has the weakest masculine connotations. The weak masculine connotations of chemistry have also been reported by other studies (Archer and MacRae, 1991; Makarova and Herzog, 2015). Consequently, we could confirm the first hypothesis stating that chemistry is accorded the lowest degree of masculinity compared to math and physics.

With respect to differences between female and male students in the gender-stereotypical connotations of science, our findings illustrate that female secondary school students perceive all three subjects considerably more strongly as a male domain than do male students. These findings are consonant with findings of previous studies on strong associations of math and physics with the male gender among female adolescents (Nosek et al., 2002; Kessels, 2005; Kessels et al., 2006; Steffens et al., 2010). In addition, our results illustrate that male students regard only math as strongly masculine, whereas physics and chemistry have a comparably low score on the masculinity index. Thus, our findings confirm our second hypothesis by showing that the association of the three science subjects with masculine traits are stronger among female students.

With regard to the impact of the masculinity image of math and science on secondary students' career aspirations, the findings of our study show that young women who potentially chose STEM as a field of study at university perceived all three school subjects-math, physics, and chemistry-as less masculine than did those young women who chose other majors. Moreover, our results suggest that among female students a strong masculine image of math and science decreases the likelihood of choosing a STEM major at university. These 
findings propose that masculine traits associated with science subjects at school constitute a major obstacle, particularly for young women's self-identification with science (Nosek et al., 2002; Cundiff et al., 2013) and for their aspirations to become researchers (Šorgo et al., 2018). Regarding the career aspirations of young women, our study supports the notion that stereotypical beliefs about math and science prevent young women from entering a STEM career (Lane et al., 2012; Ramsey, 2017).

Finally, our results on the career aspirations of young men in relation to the stereotypical gender connotations of school subjects show that young men with non-STEM career aspirations perceived only math but not science subjects as significantly more strongly masculine than did young men who chose a STEM major. Furthermore, a strong association of math with masculine traits negatively affected male students' STEM career aspirations. These findings suggest that young men who opted for non-STEM majors do not fit the masculinity stereotype and therefore the strong masculine connotations of math may have an inhibiting impact on their career aspirations similar to that on the STEM career aspirations of young women. A possible interpretation of these findings is that, among young women as well as among young men, the lack of similarity between their self-image and the image of an academic subject not only affects their choice of specialization in secondary school (Kessels, 2005; Kessels et al., 2006; Taconis and Kessels, 2009) but also leads to a lower probability of choosing those subjects in their further educational career.

Overall, the findings of our study confirm our third hypothesis by illustrating that the higher the extent of association of STEMschool subjects with masculine traits, the lower is the likelihood to enroll in a STEM major at university-both for female and male students. However, our findings also suggest that genderscience stereotypes have a stronger negative impact on the STEM aspirations of female than male students because a strong masculine image of math and science significantly decrease the likelihood of choosing a STEM major among female students, whereas only a strong masculine image of math significantly decrease the likelihood of enrollment in a STEM major among male students.

Our findings have some implications for overcoming the gender disparities in STEM. As the gender-related image of an academic discipline has a considerable effect on young people's career aspirations, a critical evaluation of the school subjects' image might be one way to break through the gender-imagedriven limitations of the career horizons of female and male students. For example, a study in Computer Science has shown that women's interest in studying Computer Science can be increased through a change of image of this academic discipline (Cheryan et al., 2013). The image of a school subject can, for example, be depicted in school textbooks. An empirical analysis of science textbooks in secondary education not only illustrated the overrepresentation of male protagonists but also revealed stereotypical portrayals of science and scientists (Makarova et al., 2016a). Since stereotypic representations in textbooks have an effect on male and female secondary school students' understanding of and anxiety about science (Good et al., 2010), an effort needs to be made to overcome stereotypical gender representations in textbooks at all educational levels. Especially since decisions to enroll in a field of study or choose a field of work in vocational education are made relatively late, and since gender images of school subjects have most likely by then been internalized and settled, reflections about gender stereotypical images of math and science subjects should preferably be encouraged in early childhood. For example, a study by Archer et al. (2010) suggested that although young children do not have profound knowledge about science subjects, they attribute masculine traits to science at an early age. Moreover, gender stereotypical beliefs should be also tackled among teachers and other gatekeepers who are potentially involved in the development of vocational interests among children and secondary students. As the study of Thomas (2017) showed, a teacher's implicit science-is-male stereotype can contribute to gender differences in female students' motivational beliefs and probably also their gendered educational choices. Finally, Else-Quest et al. (2010) suggest that proximal factors such as quality of teaching mediate the effect of gender inequality on math achievement. Thus, rise in gender equity in education can also promote boys' academic development.

Our study is subject to a few limitations. Firstly, our study has a cross sectional design and is, therefore, limited to suggesting a causal relationship between the masculinity image of science and youth career aspirations. Secondly, our study assesses the career aspirations of secondary school students and not their actual enrollment in particular majors at the university. Although this operationalization of career choice has been applied by other studies (Nagy et al., 2006; Watt, 2006), it does not exclude the possibility that the anticipated choice of a study major does not necessarily lead to the actual choice of the same major after enrollment at university. Thirdly, we should note that our study applies an explicit assessment of masculinity connotations of school subjects by using a semantic differential with 25 opposite semantic meanings. Thus, we cannot rule out that an open-ended questionnaire on masculinity image would yield different results on the semantic connotations and the strength of masculinity of the target school subjects. Moreover, we calculated the masculinity index based on the similarity of the semantic profiles of the term man and the corresponding subject term. As the present study does not include measures of the semantic ratings of the term woman we cannot compare the attribution of the feminine traits to chemistry, math and physics and its impact on the STEM study choice. Finally, the gender-related image of school subjects and their implications are one of several determinants that affect the career aspirations of male and female secondary school students. Since we did not control for other potential determinants in the explanatory models (e.g., self-image of students, their abilities, or interest in science), our results are limited to the investigation of the impact of gender-science stereotype on students' aspirations. It has been demonstrated that further school-related factors, such as the instructional design of science classes (Aeschlimann et al., 2016), teachers' support and encouragement (Aeschlimann et al., 2015) as well as family-related factors, and also peers can considerably influence the career-choice decisions of young people (Makarova et al., 2016b). 


\section{AUTHOR CONTRIBUTIONS}

All authors listed have made a substantial, direct and intellectual contribution to the work, and approved it for publication.

\section{REFERENCES}

Aeschlimann, B., Herzog, W., and Makarova, E. (2015). Frauen in MINT-Berufen: Retrospektive Wahrnehmung des mathematisch-naturwissenschaftlichen Unterrichts auf der Sekundarstufe I [Women in STEM professions: retrospective perception of mathematics and science in secondary school education]. Zeitschr. Bildungsfor. 5, 37-49. doi: 10.1007/s35834-014-0111-y

Aeschlimann, B., Herzog, W., and Makarova, E. (2016). How to foster students' motivation in mathematics and science classes and promote students' STEM career choice. A study in Swiss high schools. Int. J. Educ. Res. 79, 31-41. doi: 10.1016/j.ijer.2016.06.004

Archer, J., and MacRae, M. (1991). Gender perceptions of school subjects among 10-11-year-olds. Br. J. Educ. Psychol. 61, 99-103. doi: 10.1111/j.2044-8279.1991.tb00965.x

Archer, L., DeWitt, J., Osborne, J., Dillon, J., Willis, B., and Wong, B. (2010). "Doing" science versus "being" a scientist: examining 10/11-year-old schoolchildren's constructions of science through the lens of identity. Sci. Educ. 94, 617-639. doi: 10.1002/sce.20399

BlaŽev, M., Karabegović, M., Burušić, J., and Selimbegović, L. (2017). Predicting gender-STEM stereotyped beliefs among boys and girls from prior school achievement and interest in STEM school subjects. Soc. Psychol. Educ. 20, 831-847. doi: 10.1007/s11218-017-9397-7

Bubany, S. T., and Hansen, J. I. C. (2011). Birth cohort change in the vocational interests of female and male college students. J. Vocat. Behav. 78, 59-67. doi: 10.1016/j.jvb.2010.08.002

Chambers, D. W. (1983). Stereotypic images of the scientist: the draw-a-scientist test. Sci. Educ. 67, 255-265. doi: 10.1002/sce.3730670213

Charles, M., and Bradley, K. (2009). Indulging our gendered selves? Sex segregation by field of study in 44 countries. Am. J. Sociol. 114, 924-976. doi: $10.1086 / 595942$

Cheryan, S., Plaut, V. C., Handron, C., and Hudson, L. (2013). The stereotypical computer scientist: gendered media representations as a barrier to inclusion for women. Sex Roles 69, 58-71. doi: 10.1007/s11199-013-0296-x

Cundiff, J. L., Vescio, T. K., Loken, E., and Lo, L. (2013). Do genderscience stereotypes predict science identification and science career aspirations among undergraduate science majors? Soc. Psychol. Educ. 16, 541-554. doi: $10.1007 / \mathrm{s} 11218-013-9232-8$

Cvencek, D., Meltzoff, A. N., and Greenwald, A. G. (2011). Math-gender stereotypes in elementary school children. Child Dev. 82, 766-779. doi: 10.1111/j.1467-8624.2010.01529.x

Deaux, K., and LaFrance, M. (1998). "Gender," in The Handbook of Social Psychology, eds D.T. Gilbert, S.T. Fiske, and G. Lindzey (New York, NY: Mc Graw-Hill), 788-827.

Eagly, A. H., and Wood, W. (2012). "Social role theory," in Handbook of Theories of Social Psychology, eds P. van Lange, A. Kruglanski, and E. T. Higgins (Thousand Oaks, CA: Sage), 458-476. doi: 10.4135/9781446249222.n49

Eccles, J. S. (1994). Understanding women's educational and occupational choices. Psychol. Women Q. 18, 585-609. doi: 10.1111/j.1471-6402.1994.tb01049.x

Eccles, J. S., and Wigfield, A. (2002). Motivational beliefs, values, and goals. Annu. Rev. Psychol. 53, 109-132. doi: 10.1146/annurev.psych.53.100901.135153

Else-Quest, N. M., Hyde, J. S., and Linn, M. C. (2010). Cross-national patterns of gender differences in mathematics: a meta-analysis. Psychol. Bull. 136, 103-127. doi: $10.1037 / \mathrm{a} 0018053$

Ertl, B., Luttenberger, S., and Paechter, M. (2017). The impact of gender stereotypes on the self-concept of female students in stem subjects with an underrepresentation of females. Front. Psychol. 8:703. doi: 10.3389/fpsyg.2017.00703

Finson, K. D. (2002). Drawing a scientist: what we do and do not know after fifty years of drawings. Sch. Sci. Math. 102, 335-345. doi: 10.1111/j.1949-8594.2002.tb18217.x

\section{FUNDING}

The authors gratefully acknowledge the Swiss National Science Foundation for financial support of the study Gender atypical careers of young women (Grant no. 4060-129279).

Fort, D. C., and Varney, H. L. (1989). How students see scientists: mostly male, mostly white, and mostly benevolent. Sci. Child. 26, 8-13.

FSO (2012). Abschlüsse der universitären Hochschulen und Fachhochschulen: Basistabellen [University Diploma and University of Applied sciences Diploma: Tables]. Available online at: https://www.bfs.admin.ch/bfs/de/ home/statistiken/bildung-wissenschaft/bildungsabschluesse/tertiaerstufehochschulen/universitaere.assetdetail.5626778.html (accessed February 14, 2016).

FSO (2013). On the Way to Gender Equality. Current Situation and Developments. Neuchâtel: FSO. Available online at: https://www.bfs.admin.ch/bfs/de/home/ statistiken/kataloge-datenbanken/publikationen.assetdetail.349122.html (accessed October 10, 2018).

FSO (2019a). Students of Applied Universities (Basis Table). Available online at: www.bfs.admin.ch/bfs/de/home/statistiken/kataloge-datenbanken/tabellen. assetdetail.4762125.html (accessed November 11, 2018).

FSO (2019b). High School Diplomas According to Main Subject, School Canton, Canton of Residence and Gender (Interactive Tables). Available online at: https://www.pxweb.bfs.admin.ch/pxweb/de/px-x-1503020200_102/ px-x-1503020200_102/px-x-1503020200_102.px (accessed December 1, 2018).

George, D., and Mallery, P. (2016). IBM SPSS Statistics 23 Step by Step: A Simple Guide and Reference. New York, NY: Routledge. doi: 10.4324/97813155 45899

Good, J. J., Woodzicka, J. A., and Wingfield, L. C. (2010). The effects of gender stereotypic and counter-stereotypic textbook images on science performance. J. Soc. Psychol. 150, 132-147. doi: 10.1080/00224540903366552

Gottfredson, L. S. (2002). Gottfredson's theory of circumscription, compromise, and self-creation. Career Choice Dev. 4, 85-148.

Gottfredson, L. S. (2005). “Applying Gottfredson's theory of circumscription and compromise in career guidance and counseling," in Career Development and Counselling: Putting Theory and Research to Work, eds S.D. Brown, and R.W. Lent (Hoboken, NJ: John Wiley and Sons), 71-100.

Greenwald, A. G., McGhee, D. E., and Schwartz, J. L. (1998). Measuring individual differences in implicit cognition: the implicit association test. J. Pers. Soc. Psychol. 74, 1464-1480. doi: 10.1037/0022-3514.74.6.1464

Hand, S., Rice, L., and Greenlee, E. (2017). Exploring teachers' and students' gender role bias and students' confidence in STEM fields. Soc. Soc. Psychol. Educ. 20, 929-945. doi: 10.1007/s11218-017-9408-8

Hannover, B., and Kessels, U. (2004). Self-to-prototype matching as a strategy for making academic choices. Why high school students do not like math and science. Learn. Instr. 14, 51-67. doi: 10.1016/j.learninstruc.2003. 10.002

Hartung, P. J., Porfeli, E. J., and Vondracek, F. W. (2005). Child vocational development: a review and reconsideration. J. Vocat. Behav. 66, 385-419. doi: $10.1016 /$ j.jvb.2004.05.006

Heise, D. R. (1970). "The semantic differential and attitude research," in Attitude Measurement, ed. G.F. Summers (Chicago: Rand McNally), 235-253.

Herzog, W., Labudde, P., Neuenschwander, M. P., Violi, E., and Gerber, C. (1998). Koedukation im physikunterricht. Schlussbericht [Coeducation in Physics Class. Final report]. Universität Bern: Abteilung für Pädagogik/Abteilung für das Höhere Lehramt, Bern.

Hofstätter, P. R. (1973). Einführung in die Sozialpsychologie [An Introduction in Social Psychology]. Stuttgart: Kröner.

Huber, R. A., and Burton, G. M. (1995). What do students think scientists look like? Sch. Sci. Math. 95, 371-376. doi: 10.1111/j.1949-8594.1995.tb1 5804.x

Jones, B., Ruff, C., and Paretti, M. (2013). The impact of engineering identification and stereotypes on undergraduate women's achievement and persistence in engineering. Soc. Soc. Psychol. Educ. 16, 471-493. doi: $10.1007 /$ s11218-013-9222-x 
Kessels, U. (2005). Fitting into the stereotype: how gender-stereotyped perceptions of prototypic peers relate to liking for school subjects. Eur. J. Psychol. Educ. 20, 309-323. doi: 10.1007/BF03173559

Kessels, U., Rau, M., and Hannover, B. (2006). What goes well with physics? Measuring and altering the image of science. Br. J. Educ. Psychol. 76, 761-780. doi: 10.1348/000709905X59961

Kessels, U., and Taconis, R. (2012). Alien or alike? How the perceived similarity between the typical science teacher and a student's self-image correlates with choosing science at school. Res. Sci. Educ. 42, 1049-1071. doi: 10.1007/s11165-011-9230-9

Koenig, A. M., and Eagly, A. H. (2014). Evidence for the social role theory of stereotype content: observations of groups' roles shape stereotypes. J. Personal. Soc. Psychol. 107:371. doi: 10.1037/a0037215

Lane, K. A., Goh, J. X., and Driver-Linn, E. (2012). Implicit science stereotypes mediate the relationship between gender and academic participation. Sex Roles 66, 220-234. doi: 10.1007/s11199-011-0036-z

Makarova, E., Aeschlimann, B., and Herzog, W. (2016a). "Wenn Frauen in MINTStudiengängen fehlen: mathematisch-naturwissenschaftlicher Unterricht und die Studienwahl junger Frauen [When women lack from STEM courses: teaching mathematics and Natural sciences and Young Women's Study Choices]," in Berufsorientierung und Geschlecht [Vocational orientation and gender], ed. H. Faulstich-Wieland (Weinheim: Juventa-Verlag), 39-57.

Makarova, E., Aeschlimann, B., and Herzog, W. (2016b). Ich tat es ihm gleich - Vorbilder junger Frauen mit naturwissenschaftlich-technischer Berufswahl ["I did it like he did" - role models of young women with science and technical vocational choices]. Berufs- und Wirtschaftspädagogik online. Spezial 12, Berufsorientierung im Lebenslauf - theoretische Standortbestimmungen und empirische Analysen [Career orientation in the life course - theoretical approaches and empirical analyses], 1-19.

Makarova, E., and Herzog, W. (2015). Trapped in the gender stereotype? The image of science among secondary school students and teachers. Equal. Diver. Inclu. Int. J. 34, 106-123. doi: 10.1108/EDI-11-2013-0097

McCullagh, P., and Nelder, J. (1989). Generalized Linear Models, 2nd Edn. Boca Ration, FL: CRC Press. doi: 10.1007/978-1-4899-3242-6

Mead, M., and Metraux, R. (1957). Image of the scientist among high-school students. Science 126, 384-390. doi: 10.1126/science.126.3270.384

Miller, D. I., Eagly, A. H., and Linn, M. C. (2015). Women's representation in science predicts national gender-science stereotypes: evidence from 66 nations. J. Educ. Psychol. 107, 631-644. doi: 10.1037/edu0000005

Miller, D. I., Nolla, K. M., Eagly, A. H., and Uttal, D. H. (2018). The development of children's gender-science stereotypes: a meta-analysis of 5 decades of US draw-a-scientist studies. Child Dev. 89, 1943-1955. doi: 10.1111/cdev. 13039

Millon, T., Lerner, M. J., and Weiner, I. B. (2003). Handbook of Psychology: Personality and Social Psychology, Vol. 5. Mishawaka: Wiley and Sons.

Nagy, G., Garrett, J., Trautwein, U., Cortina, K. S., Baumert, J., and Eccles, J. S. (2008). "Gendered high school course selection as a precursor of gendered careers: the mediating role of self-concept and intrinsic value," in Gender and Occupational Outcomes, eds H. M. G. Watt and J. S. Eccles (Washington, DC: American Psychological Association), 115-143. doi: 10.1037/11706-004

Nagy, G., Trautwein, U., Baumert, J., Köller, O., and Garrett, J. (2006). Gender and course selection in upper secondary education: effects of academic self-concept and intrinsic value. Educ. Res. Eval. 12, 323-345. doi: 10.1080/13803610600765687

Neuhaus, J., and Borowski, A. (2018). Self-to-prototype similarity as a mediator between gender and students' interest in learning to code. Int. J. Gen. Sci. Technol. 10, 233-252.

Nosek, B. A., Banaji, M. R., and Greenwald, A. G. (2002). Math= male, $\mathrm{me}=$ female, therefore math $\neq$ me. J. Pers. Soc. Psychol. 83:44. doi: 10.1037/0022-3514.83.1.44

Nosek, B. A., Smyth, F. L., Sriram, N., Lindner, N. M., Devos, T., Ayala, A., et al. (2009). National differences in gender-science stereotypes predict national sex differences in science and math achievement. Proc. Natl. Acad. Sci. U. S. A.106, 10593-10597. doi: 10.1073/pnas.0809921106
OECD (2006). Evolution of Student Interest in science and Technology Studies. Policy Report. Available online at: www.oecd.org/dataoecd/16/30/36645825.pdf (accessed October 10, 2018).

OECD (2012). Closing the Gap. Act Now. Paris: OECD Publishing. doi: $10.1787 / 9789264179370$-en

OECD (2017). The Pursuit of Gender Equality: An Uphill Battle. Paris: OECD Publishing. doi: 10.1787/9789264281318-en

Osgood, C. E., Suci, G. J., and Tannenbaum, P. H. (1957). The Measurement of Meaning. Urbana: University of Illinois Press.

Ramsey, L. R. (2017). Agentic traits are associated with success in science more than communal traits. Pers. Individ. Dif. 106, 6-9. doi: 10.1016/j.paid.2016.10.017

Ratschinski, G. (2009). Selbstkonzept und Berufswahl. Eine Überprüfung der Berufswahltheorie von Gottfredson an Sekundarschülern [Self-concept and career choice. A review of Gottfredson's career choice theory among secondary school students]. Münster: Waxmann.

Renfrow, D. G., and Howard, J. A. (2013). "Social psychology of gender and race," in Handbook of Social Psychology, eds. J. DeLamater, and A. Ward (Dordrecht: Springer), 491-531. doi: 10.1007/978-94-007-6772-0_17

Rosser, S. V. (2012). Breaking Into the Lab: Engineering Progress for Women in Science. New York, NY: NYU Press. doi: $10.18574 /$ nyu/9780814776452.001.0001

Scherz, Z., and Oren, M. (2006). How to change students' images of science and technology. Sci. Educ. 90, 965-985. doi: 10.1002/sce. 20159

Šorgo, A., Dojer, B., Golob, N., Repnik, R., Repolusk, S., Pesek, I., et al. (2018). Opinions about STEM content and classroom experiences as predictors of upper secondary school students' career aspirations to become researcher or teachers. J. Res. Sci. Teach. 55, 1-21. doi: 10.1002/tea.21462

Steffens, M. C., Jelenec, P., and Noack, P. (2010). On the leaky math pipeline: comparing implicit math-gender stereotypes and math withdrawal in female and male children and adolescents. J. Educ. Psychol. 102:947. doi: $10.1037 / \mathrm{a} 0019920$

Taconis, R., and Kessels, U. (2009). How choosing science depends on students' individual fit to the "science culture." Int. J. Sci. Educ. 31, 1115-1132. doi: 10.1080/09500690802050876

Thomas, A. E. (2017). Gender differences in students' physical science motivation: are teachers' implicit cognitions another piece of the puzzle? Am. Educ. Res. J. 54, 35-58. doi: 10.3102/0002831216 682223

Watt, H. M. G. (2006). The role of motivation in gendered educational and occupational trajectories related to maths. Educ. Res. Eval. 12, 305-322. doi: $10.1080 / 13803610600765562$

WEF (2017). The Global Gender Gap Report. WEF. Available online at: https:www3.weforum.org/docs/WEF_GGGR_2017.pdf (accessed November 11, 2018).

Weinreich-Haste, H. (1981). "The image of science," in The Missing Half: Girls and Science Education, ed A. Kelly (Manchester, UK: Manchester University Press), 216-229.

Worell, J. (2001). Encyclopedia of Women and Gender: Sex Similarities and Differences and the Impact of Society on Gender. San Diego, CA: Academic Press.

Conflict of Interest Statement: The authors declare that the research was conducted in the absence of any commercial or financial relationships that could be construed as a potential conflict of interest.

Copyright () 2019 Makarova, Aeschlimann and Herzog. This is an open-access article distributed under the terms of the Creative Commons Attribution License (CC BY). The use, distribution or reproduction in other forums is permitted, provided the original author(s) and the copyright owner(s) are credited and that the original publication in this journal is cited, in accordance with accepted academic practice. No use, distribution or reproduction is permitted which does not comply with these terms. 